\title{
AS FORMAS ERÓTICAS EM SIMMEL
}

\author{
Miriam Dolzani ${ }^{1}$
}

RESUMO: Este artigo pretende sistematizar algumas das discussões que Georg Simmel desenvolveu sobre a temática das relações amorosas indo além dos pensamentos contidos em Filosofia do amor, buscando encontrar considerações pertinentes também em textos onde esta questão é secundária ou pontual. O principal objetivo é construir uma síntese da teoria das relações amorosas em Simmel, segundo os próprios pressupostos metodológicos deste autor, em termos de forma e conteúdo.

PALAVRAS-CHAVE: Simmel, Amor, Coquetismo, Teoria Sociológica.

Recebido em: outubro de 2012

Aceito em: março de 2013

Para citar este artigo:

DOLZANI, Miriam; As formas eróticas em Simmel. In: Revista Intratextos, 2013, vol 4, no1, p. 180-193. DOI: 10.12957/intratextos.2013.8586

1 Doutoranda em Ciências Sociais (2012). Mestre em Ciência Política pela UFRJ (2010). Mestre em Ciências Sociais pela UERJ (2008). Especialista em Políticas Territoriais do Estado do Rio de Janeiro pelo IGEO/UERJ (2007). Bacharel e Licenciada em Ciências Sociais pela UERJ (2006). Atualmente é professora adjunta FEUC, da FAETEC. Áreas de Pesquisa: Subjetividade, relações de gênero e relações raciais. Email: miriamdolzani@hotmail.com 


\section{Apresentação}

A Sociologia de Georg Simmel (1958-1918) representa um pensamento ímpar no interior das Ciências Sociais, ajudando a compor o quadro da Sociologia clássica alemã, ao lado de Karl Marx e Max Weber. No entanto, ao contrário destes, a produção de Simmel não é tão popularizada nos estudos acadêmicos brasileiros ${ }^{2}$. O fato de ser menos estudado que seus compatriotas pode dar a falsa impressão de que Simmel elaborou uma obra reduzida ou pouco relevante sobre os temas da Sociologia, equívoco que se desfaz logo que o esforço de investigar a sua obra se inicia.

Simmel ingressou na Universidade de Berlim aos 18 anos e defendeu sua dissertação doutoral em 1881. De 1885 a 1900 atuou como Livre-docente nesta mesma Universidade, firmando-se como conferencista de grande popularidade. Sem qualquer vínculo formal, ganhava apenas uma taxa por cada aluno inscrito em seus cursos. Aos quarenta e dois anos de idade, foi promovido a Professor Extraordinário, ainda sem entrar nos quadros permanentes de Berlim, e assim permaneceu por mais 14 anos. Somente em 1914 foi convocado para Estrasburgo, onde veio a falecer quatro anos depois. Sua trajetória acadêmica reflete um pouco das opiniões controversas existentes em relação a sua obra ${ }^{3}$.

Suas publicações em vida datam da década de 80 do século XIX e se entendem até os últimos anos de sua vida, demonstrando intensa atividade intelectual e originando mais de 200 artigos e 20 livros. Simmel teve sua obra amplamente divulgada em língua inglesa e francesa, sob diversos meios e de maneira fragmentada, o que dificulta a exata cronologia da realização de suas obras.

Dos originais simmelianos que geraram os títulos revisados para construir este artigo, destaca-se Soziologie: Untersuchungen über die Formen der Vergesellschaftung, de 1908, que foi base textual para The Sociology of Georg Simmel, traduzido para a língua inglesa em

\footnotetext{
${ }^{2}$ Em uma busca simples por assunto, digitando as palavras "Weber", "Marx", "Simmel" no portal da Capes, no setor de Banco de Teses, encontram-se os seguintes números, respectivamente: 4.126, 1.261 e 102 referências. Ao realizar o mesmo tipo de busca no portal Scielo, que reúne artigos de diversas revistas cientificas da área das Ciências Sociais, os números encontrados, também respectivamente são: 472, 224 e 16.

3 Ver as diversas qualidades que eram imprimidas à Georg Simmel por seus expositores em MORAES FILHO, Evaristo de (org.) Georg Simmel. Sociologia. São Paulo. Ática. 1983. Pg. 12.
} 
1950, e que foi a principal fonte de O Problema da Sociologia (1983), na edição aqui utilizada. The Conflict in Modern Culture (1971) deriva de Der Konflikt der Modernen Kultur, editado em alemão pela primeira vez em 1918, e constitui outro texto importante para este trabalho.

No conjunto de sua obra, Simmel toca em muitos temas caros às Ciências Sociais, aprofundando-se em matérias fundadoras do pensamento social. Formas e conteúdos sociais, método, subjetividade, conflitos sociais, religião, individualismo, grupos sociais, sistemas de trocas, capitalismo e liberdade são alguns dos temas primordiais que permeiam o pensamento dos grandes clássicos e que também estão presentes na obra deste autor.

Talvez o que há na produção de Simmel, que o diferencie dos outros clássicos, é a liberdade de pensamento que imprime aos seus textos, muito mais borrando do que traçando limites com outras áreas de saber. Outro dado importante em Simmel é a sua aproximação com a teoria do conhecimento Kantiana, permitindo com que ele defina premissas como quem constata realidades empíricas.

O seu estudo das formas e conteúdos da vida social possui ares concretistas. Ao percorrer alguns de seus textos, logo é perceptível a sua forma antitética, sintética e paradoxal, que coloca o leitor em uma espiral que sempre retorna ao mesmo ponto formal, para dele partir novamente. Os conteúdos são variados e mesmo inusitados. O estudo do coquetismo é um dos exemplos mais significativos dessa característica. Nele, somos convidados a participar de uma relação erótica que soma provocação e recusa, resumida na forma de variação contínua da distância. É quando o conteúdo íntimo da sedução é transformado em cálculo espacial.

Em termos de condução do leitor, a espiral parece ser mesmo uma boa definição. No texto "A Aventura", por exemplo, o leitor é levado a uma sequência tão atordoante de conexões causais e paradoxais simultâneas, que de fato parecemos sentir a pulsação da aventura. Se no coquetismo o movimento de balanço seria melhor para definir a sensação mental do leitor, um percurso pelas corredeiras de um rio poderia descrever bem o desenho espacial proposto por Simmel para explicar o sentido da aventura.

Os objetos são variados e heterodoxos, o que facilita o trabalho de investigar uma questão também heterodoxa. As relações eróticas são temas recorrentes nos textos simmelianos. A proposta aqui é sistematizar em termos de forma e conteúdo algumas das 
discussões que este autor realiza sobre a temática das relações amorosas indo além dos textos reunidos em Filosofia do amor, dedicado especificamente a esta temática, buscando encontrar considerações pertinentes mesmo em textos que esta questão é secundária ou pontual.

Sem ambicionar realizar uma análise de grande abrangência sobre a teoria do amor em Simmel, pela brevidade e caráter ensaístico desse texto, almeja-se, ainda assim, construir uma síntese que represente uma porção do pensamento do autor sobre este tema, segundo seus próprios pressupostos metodológicos.

\section{O Coquetismo}

Psicologia do Coquetismo (1993), cuja edição original data de 1909 no título Psychologie der Koketterie, foi escolhido para iniciar a discussão sobre o erotismo em Simmel, uma vez que este tipo de forma social corresponde a um momento anterior a consumação do amor que não deseja se realizar enquanto relação, se assim pode-se dizer. $\mathrm{O}$ Coquetismo corresponde a um tipo específico de comportamento da mulher coquete, que pretende seduzir os homens sem que com isso, essa ação siga o seu caminho natural do envolvimento.

A originalidade do texto sobre coquetismo não está exatamente em perceber e registrar esta forma de ralação social, mas sim em colocá-la em termos espaciais e contraditórios. $\mathrm{Na}$ maioria de seus trabalhos, como poderemos avaliar, Simmel imprime a lógica da contradição na evolução da discussão sobre o objeto tratado. Primeiramente, ele apresenta uma tese, depois uma antítese e conclui em uma síntese contraditória. Neste caso, a definição do coquetismo por excelência já é um paradoxo:

Porque o próprio desta última (a coquete) é desprezar o prazer e o desejo por meio de uma antítese/síntese original, através de alternância ou da concomitância de atenções ou ausências de atenções, sugerindo simbolicamente o dizer-sim e o dizernão, que atuam como que "à distância", pela entrega ou recusa - ou, para falar em termos platônicos, pelo ter e o não-ter -, que ela expõe uma a outra, ao mesmo tempo que as faz experimentar como que a uma só vez. (p. 95, 1993).

Cada ato de atenção da coquete só tem valor porque ele poderia não ser ofertado, poderia não se realizar. A negação simples também não interessa, neste caso, a ausência de atenção da mulher que não está ali para seduzir também não constitui coquetismo. A intensidade da relação com a mulher coquete é que o não está contido no sim, e o sim está contido no não. Mesmo quando ela se aproxima é sabido para ambos a condição da não 
concretização da relação, e nem por isso o coquetismo perde seu valor, pois a realização concreta não está em jogo para ambos.

A questão do desejo é fundamental para prática do coquetismo. Quando cita o amor platônico para introdução às suas ideias, Simmel fala sobre a vivência do estado intermediário entre o ter e o não ter. A princípio, desejar é desejar obter, porém quando obtido o objeto do desejo, a caçada deixa de existir. O coquetismo corresponderia à festa da caça, da dúvida e da incerteza, que precisa ter operações de distanciamento e aproximações exatos, para que a presa não perca seu valor nem pela conquista e nem pela impossibilidade. É um jogo que se sabe jogo e vivido enquanto realidade, com regras próprias acordadas por ambos.

O movimento é o grande sentido espacial do coquetismo. A incerteza da conquista é conseguida através das pistas dúbias que a mulher coquete oferta ao seu admirador. O olhar não direto que deixa dúvidas sobre o que exatamente é vislumbrado. O movimento excitante que não se sabe intencional. A postura de distância e reserva fazem viver o desejo daquele que possui uma dúvida que não quer ser sanada, pois o percurso faz-se muito mais fascinante do que a linha de chegada.

O coquetismo é fundamentalmente uma forma de relação social, segundo Simmel. Entretanto, se fôssemos investigar algum tipo de conteúdo neste comportamento ficaríamos com pelo menos duas respostas.

Na primeira delas, é preciso ir a outro texto de Simmel. Em A Tragédia da Cultura (1998), o autor fala do gosto pelo jogo como uma sofisticação do desenvolvimento da alma. Ao sofisticar as modalidades das formas sociais, o indivíduo poderia desenvolver um apreço pela própria forma das relações, para além do conteúdo. Assim, o impulso responsável pelo coquetismo, assim como no jogo, estaria na própria prática da forma social, gozando de um sofisticado estado de desenvolvimento da alma.

Se a opção é restringir-se ao texto, a resposta sobre o conteúdo do coquetismo invariavelmente volta-se para a questão do gênero. Simmel fala em uma natureza feminina centrada em si mesma, reunida em torno de um ou vários pontos. Essas características fariam com que as mulheres tivessem muito mais facilidade de guardar em si as faculdades do sim e do não ao mesmo tempo, facilitando seu estado de hesitação e incerteza perante a investida masculina. A natureza masculina estaria muito mais diferenciada, e objetivamente voltada 
para fora. $\mathrm{O}$ homem teria, então, um imenso gosto pela unidade que é representado pelo simultâneo sim e o não, concentrado na figura feminina.

\begin{abstract}
Nesse modelo que dá forma à contribuição da mulher à relação entre os sexos, nesse sim e não, revela-se o sentido profundo dessa interpretação do amor que faz dele o meio termo entre o ter e o não ter. Como, aqui, o não-ter entrou no ter, ambos constituem a face de uma unidade relacional, cuja forma mais extrema e mais apaixonada é finalmente a posse do que, ao mesmo tempo, não se possui. (1993, p. 107)
\end{abstract}

O impulso em direção à unidade surge na Psicologia do Coquetismo como principal justificativa para o jogo estabelecido com a coquete, e surgirá também revestido de vários outros modos em seus demais trabalhos. Aqui, ele aparece sob as formas puras do sim e do não, mas, ao seguirmos adiante, veremos que o conteúdo da forma unidade pode se alterar diversas vezes, desde que conserve sua natureza de união de contraditórios e finalidade básica de todos os impulsos.

\title{
A Aventura do amor
}

A Aventura (2004), traduzido da biografia e coletânea Georg Simmel 1859-1918 (1959), talvez seja o texto mais concretista de Georg Simmel. Em vários momentos exige um esforço maior do leitor para que este não seja enredado na forma literária de Simmel desprendendo-se completamente de seu conteúdo. Simmel imprimiu tanta velocidade e ritmo às suas palavras que por vezes é possível sentir a sua mensagem pulsar em significado.

A tese principal do autor neste episódio é que a experiência da vida se dá em duplo sentido. O primeiro deles é dado pelo imediato ser-vivido, representando uma potência que gira em torno de seu próprio centro. No segundo sentido, está inserida no percurso vital, delimitado, parte de um projeto total. No desenrolar do texto, Simmel explicita de vários modos qual o sentido da aventura no conjunto total da vida.

O caráter da aventura pousa-se no excepcional, no único, no invulgar. Naquilo que é absolutamente descolado do fluxo contínuo da vida. Aquilo que, de tão insólito, pulsa e sobrevoa a narrativa ordinária da vida. Simmel compara a experiência da aventura com o sonho, pois ambos provocam a descentralização do "eu" jogando-o para fora de seu eixo principal.

Enquanto o projeto total da vida segue um trajeto linear, com ricas conexões com o que lhe é anterior e posterior, a aventura mais se assemelharia a um ponto nodal, sem 
correlações com a continuidade da vida. A aventura tem princípio e fim, limites bem demarcados e no sentido simmeliano, sendo uma ilha na vida, que tendo características tão opostas à corrente da vida, representa sua negação.

Simmel afirma que a forma da aventura pode aplicar-se a uma série de conteúdos vitais e, que um dos mais expressivos deles é o conteúdo erótico. Segundo o autor, a aventura erótica deve reunir pontos quantitativos e qualitativos para se concretizar. Quantitativamente deve ser breve, em um curto espaço de tempo. Qualitativamente deve reunir qualidades psíquicas que a façam ter um tom onírico, fabuloso e extraordinário.

A relação amorosa contém claramente os dois elementos que também se unem sob a forma de aventura: a força conquistadora e a dádiva indemonstrável, o triunfo devido ao próprio talento e à submissão e à sorte, com a qual somos premiados por um elemento incalculável situado fora de nós. $(2004$, p. 10)

O fragmento acima demonstra que a aventura amorosa não é um acidente na vida do indivíduo, e que para vivenciá-la é preciso lançar-se na sorte e acreditar no êxito. Para Simmel, a aventura amorosa é uma experiência com maior sentido no universo masculino, uma vez que exige a diferenciação entre o que está dentro do retilíneo da vida e o que está fora. É para o conquistador e o aventureiro. Não que a mulher factualmente não viva essa experiência, mas por ser ainda indiferenciada, ela não possui tamanha distinção entre sujeito e objeto para sentir a experiência de flagrar-se fora de si. À mulher estaria reservado o gozo de conceder a si mesma ao conquistador.

Sendo pertinente ao homem a propriedade da conquista, cabe a ele também lançar-se ao incerto, ao hipotético e ao duvidoso como quem tem o calculável diante de si. E, ao obter sucesso, ele pode sorver de uma só vez todas as glórias de sua coragem e sorte. O prazer máximo desse prelúdio deseja se alongar, a aventura deseja tonar-se fluxo vital, mas como isso haverá de ser possível se ela mesma representa a total antítese do fluxo normal da vida. É como tentar reter na eternidade a sensação de ter os pulmões completamente cheios de ar, porém isso não é possível, é preciso experimentar a privação deste elemento para que o fluxo contínuo volte a se dar. Caso contrário, o máximo da vida logo significaria o seu oposto.

A questão da unidade na aventura se coloca de modo um pouco diferente dos demais textos de Simmel. Aqui, o autor vai além do método da construção do paradoxo através da união de seus contrários. $\mathrm{Na}$ Aventura, os contrários não são díspares e nem estão isolados, na verdade, são polos de uma mesma escala de conteúdos vitais comuns aos dois estados. O que irá diferenciar "vida" de "aventura" será a proporção que esses conteúdos estarão presentes 
em cada uma dessas formas. No fluxo da vida, a força diante do incontrolável e a certeza frente ao incalculável existirão da mesma forma que na aventura. No entanto, na vida contínua, essas qualidades estarão muito mais diluídas, a ponto de não serem notadas. Enquanto que na aventura agirão em tamanha concentração que tornarão fragmentos impalpáveis em totalidade da vida.

\section{Fidelidade: a união entre o individual e o social}

No título Fidelidade e Gratidão (2004), retirado do texto Faithfulness and gratitude como parte de The Sociology of Georg Simmel (1950), originário de Soziologie (1908), Simmel dá conta da estabilidade das relações sociais. Responde, com muita competência, qual é a motivação humana que permite com que laços sociais perdurem para além de toda inconstância dos impulsos vitais. Para Simmel, estão repousados nos atributos da fidelidade e da gratidão a capacidade de perpetuar vínculos que há muito perderam sua razão inicial de ser.

Simmel configura a fidelidade como uma forma sociológica de segunda ordem, pois deriva de impulsos primeiros, estes sim revestidos de diversos conteúdos. Tal é a importância desta forma de segunda ordem que o filósofo aponta que, sem a sua existência, a sociedade se desintegraria, pois não haveria formas substitutas tão potentes. Entretanto, mesmo possuindo tamanha importância, é incapaz de iniciar qualquer tipo de relação que seja. A fidelidade é dependente de forças que deram origem ao contato, resumindo-se em uma predisposição para a manutenção deste vinculo. Poderíamos chamar à fidelidade a perseverança da alma, pois ela mantém-na no caminho que a encetou, mesmo depois de a ocasião original que ele conduzira ter deixado de existir. (2004, p. 32).

O ponto neste tema é perceber que Simmel crê que relações sociais são iniciadas por sentimentos genuínos e puros, e que extinguem a função dessa relação logo que realizados. Partindo apenas dessas motivações primeiras, não existiria propósito para aquele ato continuar a se repetir indefinidamente. Uma relação erótica, por exemplo, sendo iniciada por desejo pela beleza física só poderia se manter através do tempo devido ao sentimento de fidelidade.

Se a fidelidade também é uma forma de relação social, seus conteúdos não ficam bem definidos, podendo ser sustentada por múltiplos fatores, de índole intelectual e prática, positiva e negativa. (2004, p. 13). Para ele, fator afetivo agindo na manutenção das unidades sociais funciona como um molde geral ou unitário para os mais variados interesses. Um 
reservatório psicológico para onde vão todos os sentimentos. Ou seja, uma forma social em que se cristalizam todos os sentimentos primários.

De todas as formas sociais tratadas por Simmel, possivelmente a fidelidade corresponde à forma de todas as formas, sendo a forma social por excelência. Pois, entendendo que não há forma sem conteúdo e que, no mesmo sentido, não há modo de um conteúdo se expressar sem se valer de uma forma; conceituar uma forma de relação para onde vão todos os sentimentos de preservação de vínculos iniciadas por múltiplas condições representa estabelecer uma forma social que sintetize todas as demais.

O problema do dualismo e da unidade se insere na questão da fidelidade na medida em que os sentimentos primários, que dão início às relações, estão postos em um fluxo vital em constante transformação. Os conteúdos relativos a desejos, vontades e anseios não podem ser fixados em formas estáticas sem que isso gere uma necessidade de transgressão e consequente fixação em uma nova forma, dessa vez mais adequada, mas que voltará a ser incômoda, voltando ao ponto inicial. A Sociologia de Simmel transmite todo tempo que conteúdos são mutáveis demais para caberem em formas sólidas e limitadas, no entanto, conteúdos sem forma não podem ser socializados, estando sacrificados em sua finalidade.

A nossa vida interior, que percebemos como uma corrente, como um processo incessante, como uma sucessão de altos e baixos dos pensamentos e dos estados de espírito, fica cristalizada, mesmo para nós próprios, em fórmulas e direções fixas, muitas vezes apenas pelo fato de verbalizarmos essa mesma vida. (2004, p. 40)

Quanto à unidade, tem-se a síntese paradoxal do termo fidelidade enquanto fusão das formas e conteúdos sociais. Somente o recurso psicológico da fidelidade, cristalizado em formas estáveis de relação, seria capaz de unir as circunstâncias duais de fluxo contínuo e formas sociais. Indo mais longe, a fidelidade teria como propriedade unificar duas instâncias sociologicamente opostas: o individual e o social. Seria por meio dela que as correntes vitais incessantes poderiam se consolidar ao ponto de estabelecer relação com o outro, inaugurando o social. Embora sempre desajustada, a forma social significa a única possibilidade de comunicação entre correntes vitais individuais, e a forma específica fidelidade, a única estratégia que serve à permanência desse vínculo.

\section{Ciúme: a aniquilação da unidade}

A análise sobre o ciúme na teoria simmeliana está incorporada ao exame mais amplo que o autor faz sobre o conflito, em texto presente na versão norte-americana Conflict (1955) 
e na versão espanhola Estudios sobre las formas de socialización (1964), ambos originários do capítulo IV de Soziologie (1908). Para Simmel, o conflito é uma forma social tão válida e importante quanto às outras, não havendo espaço para julgamentos morais na classificação dessas formas. Assim é porque o conflito cumpre com a mesma competência o fim básico de propiciar a associação entre os indivíduos.

Em um raciocínio paradoxal, Simmel defende que o conflito realiza o contato interpessoal com ainda mais propriedade que as outras formas de relação social, uma vez que aí os ânimos se encontram intensificados, gerando ações extremamente recíprocas. O que causa preocupação, na verdade, é o fator da dissociação, marcado pela ausência de reciprocidade, que torna os indivíduos isolados de modo definitivo. O conflito, ao contrário, permite uma solução para a unidade.

A unidade pode ocorrer de dois modos. Pela conjunção, em que os pares encontram um meio positivo de apaziguar suas pendências. Ou pelo aniquilamento, que pode significar a sobreposição de uma das forças ou mesmo seu desfecho mais trágico. De todo modo, o conflito representa o caminho para a paz e harmonia social, após uma modalidade inevitável de enfrentamento de elementos contrários. A unidade significa, então, a soma de todas as forças múltiplas e adversárias em um todo que represente a sua síntese, promovendo o equilíbrio social.

Consideramos como unidade a coincidência e coordenação dos elementos sociais, em contraposição a suas cisões, isolamentos, desarmonias. Mas também é unidade e síntese geral das pessoas, energias e formas que constituem um grupo, a totalidade final em que estão compreendidas, tanto as relações de unidade em sentido estrito, quanto as de dualidade ${ }^{4}$. (1986, p. 268. Tradução minha).

Simmel dedica um intervalo de suas reflexões sobre o conflito especialmente ao estudo do ciúme. Primeiramente faz uma diferenciação entre ciúme e inveja, que diz respeito ao objeto de desejo daquele que é tomado por essas forças. A inveja seria o conteúdo voltado mais para o objeto possuído do que para quem a possui. Enquanto que o ciúme trata do sentimento de disputa e inferioridade atribuído a alguém específico. Em outras palavras, o ciúme corresponderia ao sentimento negativo atribuído àquele que possui o que eu desejo e, por isso, se faz superior a mim. Ou seja, o ciúme tem um caráter pessoal específico e determinado.

\footnotetext{
${ }^{4}$ Tradução minha.
} 
No caso amoroso, o ciúme se funda na crença do direito de possuir alguém que por si é desejado intensamente, o direito sobre o objeto amado. Esta correlação produz um conflito em sua própria origem, pois estabelece direito sobre a vontade do outro-indivíduo, criando necessidade de certeza sobre aquilo que é incontrolável. O ciumento, por excelência é aquele que crê ter o direito de possuir. É o direito que se justifica na força do desejo.

Quando acatado pela outra parte e também recíproco, a forma do ciúme estabelece unidade. É a posse sobre si aceita, deixando de gerar contradição. Entretanto, a própria forma do ciúme retém o seu contrário. Se é preciso criar o direito sobre algo é porque naturalmente ele não me pertence. A força do ciúme, quando ativa, deixa clara a fragilidade entre agente possuidor e objeto possuído.

O que ocorre é que essa unidade, que continua existindo de forma interna ou externa, o que ao menos é sentida por uma das partes como existente, é negada, real ou idealmente. (1986, p. 299. Tradução minha). O aniquilamento da unidade na forma do ciúme ocorre porque, dubiamente, ele representa o máximo subjetivo entre a positividade e negatividade, entre o ter e o não ter.

Se o desejo intenso cria proporcional direito da posse e, por isso, uma extrema conjunção entre subjetividades sob a perspectiva de pelo menos uma das pessoas, a negação dessa posse significa a rejeição máxima daquilo que já fazia parte de si. O conflito ocorre, então, no interior do corpo privado daquele sente ciúme, passando de modo muito radical da condição de unidade inclusiva harmônica a partir do outro para a situação de total desequilíbrio e luta interna causada pelo involuntário processo de dissociação, que passa a se dar dentro de si mesmo. Neste sentido, não há luta mais profunda e violenta do que a causada pela forma social do ciúme.

O radicalismo desse processo se dá porque, distinto das outras formas sociais, o ciúme faz o caminho inverso entre dualidade e unidade. Se, nos outros exemplos, temos dualismos gerando unidades, no caso do ciúme encontra-se o mecanismo do antagonismo derivado da unidade. A trajetória inversa da unidade para a cisão, somada ao caráter privado desta luta, traria o imenso teor de pungência para essa forma social.

\section{Considerações Finais}


A narrativa deste artigo optou por seguir uma trajetória comum aos romances, em que atores imaginários aproximam-se pelo jogo do coquetismo, encantam-se no momento da aventura, firmam laços através da fidelidade e encontram seu fim na fatalidade do ciúme. A proposta deseja retomar a interpretação de Simmel sob diferentes ângulos, abrindo a discussão para um público menos restrito, para o qual a linguagem deste autor pode parecer um tanto inacessível. O tema do amor, de apelo popular e universal, mostra-se um bom exemplo para testarmos a precisão do método que está presente na teoria social simmeliana.

Conforme se pôde observar, Georg Simmel é um autor possuidor de extremo rigor metodológico na construção de suas teses. Mesmo retirando passagens sobre o amor e erotismo de quatro fontes textuais diferentes, observa-se idêntico método argumentativo para chegar às suas conclusões. Partindo sempre de ideias duais que, na verdade, representam paradoxos, Simmel nos conduz à unidade total da vida para onde parecem correr todos nossos esforços. O inevitável para Simmel é a unidade. O dualismo, seu percurso necessário.

No Coquetismo, encontramos o $\operatorname{sim}$ e o não concentrados no ser feminino indiferenciado, representando uma unidade. A Aventura destaca-se por encarnar a unidade da vida, onde estão concentrados os conteúdos e ímpetos que fazem dessa experiência algo extraordinário e único, em contraposição ao fluxo vital contínuo. A Fidelidade significa unidade por reunir em si todas as outras formas, quando estas já perderam sua razão de ser inicial, é quando as correntes vitais se estabilizam para permitir o contato social permanente. O Ciúme reflete a unidade do ser que deseja e do ser desejado no interior da subjetividade do primeiro. Porém, quando a continuidade da posse é negada pelo outro indivíduo, ocorre o sofrido processo de dilaceração do "eu" que, sem saída, obriga-se a reconhecer as diferentes naturezas de si e do outro.

Sendo assim, poderíamos sintetizar as reflexões afirmando, em termos simmelianos, que o coquetismo é o fascinante caminho para a unidade, a aventura é a concentração da unidade em uma forma específica, a fidelidade é a unidade que guarda todas as formas em si, e o ciúme é a unidade que tem como destino a tragédia de saber-se dual.

Por tudo isso, pode-se afirmar que não há uma forma social singular que expresse o conteúdo amoroso na teoria de Simmel. As relações eróticas podem se dar de várias formas, aliás como todo conteúdo no conjunto dessa análise. Os conteúdos, as forças vitais, os elementos naturais da vida parecem mutáveis e fluidos demais para serem objetos da 
sociologia. Somente as formas sociais, elas, sim, um pouco mais perenes e com suas características comunicativas e associativas constituem este autor um clássico da teoria social.

\section{Bibliografia}

MORAES FILHO, Evaristo de (org.). Georg Simmel. Sociologia. São Paulo. Ática. 1983.

SIMMEL, G. A sociabilidade. In: Questões Fundamentais da Sociologia: indivíduo e sociedade. Rio de Janeiro. Jorge Zahar Ed. 2006.

As grandes cidades e a vida do espírito. Mana, vol.11, n.2, pp. 577-591. 2005.

Fidelidade e Gratidão. In: Fidelidade e Gratidão e outros textos. Lisboa. Relógio D’Água Editores, 2004. Pg. 31-53.

- A Aventura. In: Fidelidade e Gratidão e outros textos. Lisboa. Relógio D’Água Editores. 2004. Pg. 179-197,

El concepto y la tragedia da cultura. In: Sobre la aventura: ensaios filosóficos. Barcelona. Ediciones Península. 1998.

. Psicologia do Coquetismo. In: Filosofia do Amor. São Paulo: Martins Fontes. 1993.

. Fragmento sobre o Amor. In: Filosofia do Amor. São Paulo: Martins Fontes. 1993.

. Sociologia: estudios sobre las formas de socialización. Madrid. Alianza. 1986.

O problema da sociologia. In: MORAES FILHO, E. (Org.) Simmel. São Paulo. Ed. Ática. 1983.

. On Individuality and Social Forms. Chicago. The University of Chicago Press (Parte III - "Social Types"). 1971.

. Subjective Culture. In: On Individuality and Social Forms. Chicago. The University of Chicago Press. 1971.

Freedom and the Individual. In: On Individuality and Social Forms. Chicago. The University of Chicago Press. 1971.

. The Conflict in Modern Culture. In: On Individuality and Social Forms. Chicago. The University of Chicago Press. 1971.

. Sociología: Estudios sobre las formas de socialización. Madrid. Alianza. 1986.2 v. 
Conflict \& The web of group affiliations. The Free Press. Tradução de K. H. Wolff. New York. 1955. P. 13-123.

. The Sociology of Georg Simmel. New York. The Free Press. 1950.

\section{THE EROTIC FORMS IN SIMMEL}

ABSTRACT: This article intend to systematize some of the discussions that Georg Simmel developed about the theme of relationships going beyond the thoughts contained in philosophy of love (Filosofia do Amor), seeking to find relevant considerations also in texts where this issue is secondary or occasional. The main goal is to construct a summary of the theory of love relationships in Simmel, according to the methodological assumptions of the author themselves, in terms of form and content.

KEYWORDS: Simmel, Love, coquetry, Sociological Theory. 